\title{
Interactive video games to promote physical activity among healthy children and youths
}

\author{
Aleksandra Kowaluk, Marek Woźniewski \\ Department of Physiotherapy, University School of Physical Education in Wroclaw, Wroclaw, Poland
}

\section{ABSTRACT}

Physical activity is crucial in reducing the risk of civilisation diseases: type 2 diabetes, hypertension, obesity, osteoporosis, cancer, and depression. An adequate level of physical activity during childhood prevents the development of early atherosclerotic lesions, which result from obesity, hypertension, and dyslipidaemia, frequently appearing amongst children. Most children do not meet the basic physical activity guidelines. Children spend most of their time in a sitting position, which reduces their daily energy expenditure. Interactive video games (IVG) can be an alternative and attractive form of spending free time, which may contribute to reduction of children's sedentary behaviour. The use of IVG in preventive health programs can become a way to increase the level of physical activity and reduce cardiometabolic risk factors. The aim of this study is to review the research on the impact of the IVG on the level of physical activity, sedentary behaviour, and energy expenditure of healthy children.

\section{KEY WORDS:}

child, energy expenditure, physical activity level, active video games.

\section{INTRODUCTION}

Physical activity is crucial in reducing the risk of civilisation diseases, including: type 2 diabetes, hypertension, obesity, osteoporosis, cancer, and depression. The beneficial effect of physical activity is related to its direct impact on the body's functions because it causes adaptive changes that increase the efficiency of the human organism. Physical activity also indirectly affects the body by modifying and reducing the impact of risk factors for cardiovascular diseases [1]. An adequate level of physical activity at young age protects against the development of early atherosclerotic lesions, which result from obesity, hypertension, and dyslipidaemia, which children nowadays frequently suffer from [2].
Nowadays most children and adolescents do not meet the basic guidelines for physical activity [3]. Children spend most of their time in a sitting position, which significantly reduces their daily energy expenditure; they devote their free time to screen-based activities, such as watching TV, using a computer, and playing inactive video games [4]. The recommended level of physical activity, necessary for the proper development of a child, should be moderate, occurring at least five days a week, lasting at least one hour [5]. International studies on health behaviours in school-aged children (HBSC) have shown that as many as $80 \%$ of children aged $13-15$ years did not take moderate or vigorous daily physical activity (MVPA) for at least 60 minutes. The majority of children $(66 \%$ of girls and $68 \%$ of boys) spent more than two hours a day in

\section{ADDRESS FOR CORRESPONDENCE:}

Aleksandra Kowaluk, Department of Physiotherapy, University School of Physical Education in Wroclaw, 35 Ignacego Jana Paderewskiego Ave, 51-612 Wroclaw, Poland, ORCID: 0000-0002-2471-8901,

e-mail: aleksandra.kowaluk@awf.wroc.pl 
front of a TV screen [6]. The results of other studies, conducted by a Canadian group of researchers, showed that children spent approximately 7.8 hours daily in front of computer or television screens [7]. Thus, the lack of sufficient level of physical activity occurs, and the number of overweight and obese children increases. Abnormal body weight predisposes children to an increased risk of cardiovascular diseases during adulthood [8]. To prevent the development of risk factors of such diseases, the level of children's physical activity should be even higher than international guidelines [9]. The vast majority of time spent in a sitting position, especially in front of the screen, negatively affects many health and behavioural indicators: a change in body composition, deterioration of physical fitness, low self-esteem, and problems with establishing social contacts are observed [10].

Currently, up to $91 \%$ of children and adolescents in developed countries use video games. Most often these are inactive games during which the players assume a sitting position and do not move their bodies. Such games do not increase the level of physical activity. There is also another type of games - interactive games. Interactive video games (IVG) are a type of modern electronic games that allow the player to interact physically with the image displayed on the screen during various activities, such as sport, physical exercises, dancing, or arcade games. IVG can help to reduce the time spent in a sedentary position while watching TV and playing inactive video games. Researchers from around the world are constantly monitoring the health of the population and the level of physical activity. They are trying to develop innovative programs using IVG techniques as one of the ways to solve the problem of inactivity during gaming, and to reduce sedentary behaviour $[11,12]$. Active games can be an alternative and attractive form of spending free time, which can contribute to the reduction of sedentary behaviour in a group of healthy children. IVG technology can become a complementary method to traditional forms of children's physical activity. It is possible that in the future these techniques will be used as part of primary prevention programs [13].

The aim of this study is to review the research on the assessment of the impact of IVGs on the level of physical activity, sedentary behaviour, and energy expenditure of healthy children.

\section{INTERACTIVE VIDEO GAMES - IMMEDIATE PHYSICAL ACTIVITY EFFECTS}

The evaluation of the one-off effect of IVG on the healthy children's bodies included the study of: energy expenditure (EE), physical activity level (PA), heart rate $(\mathrm{HR})$, and oxygen uptake (VO2). The levels of these parameters were compared while playing interactive and inactive video games.

\section{ENERGY EXPENDITURE}

A relatively short 20-minute IVG session effectively increases the energy expenditure (EE) of healthy children. The level of activity during an IVG is comparable in intensity to activities such as walking, jumping, or running [12]. Thanks to IVG, children become more active, and the level of this activity corresponds at least to low-intensity walking. Studies have even reported a fourfold increase in energy expenditure during the game session and the achievement of physical effort at an intensive level [11, 12, 14-20].

The level of a child's total energy expenditure during the game depends on the involvement of individual body parts in the sequence of movements. Games that engage both upper and lower limbs symmetrically cause a greater energy expenditure of a child; in the ones which favour, e.g. a dominant limb, lower total energy expenditure is observed [21]. The range and frequency of movements performed during IVG in the group of adults and children were also analysed; it was shown that children, regardless of the type of the game, moved much more, and the range of movements was more extensive compared to adults [11].

The amount of energy expenditure during an IVG presented in the form of a metabolic equivalent task (MET) was also assessed. The research results confirm that a one-off intervention with the use of the IVG generated a higher energy expenditure in children compared to the inactive game. Most of the children playing the IVG demonstrated a moderate level of physical activity $[18,22$, 23]. The boys' energy expenditure was greater than girls; this was due to their greater involvement in the game [24]. It is recommended that the daily level of physical activity of children is between 3 and 6 MET $[25,26]$. Research shows that IVGs increased the energy expenditure of children from 2 to 5 MET, which was a sign of light or moderate level of physical activity [19, 27]. McNarry et al. proved that IVG increased children's energy expenditure even above 6 MET, which corresponded to a vigorous intensity of physical activity [24].

Research by Graves et al. also showed that IVGs cause children to expend more energy compared to inactive games; however, the amount of energy spent was not as large as during traditional sport activities. Graves et al. concluded that the intensity of physical exercise during IVG was not sufficient to ensure the recommended level of daily physical activity of the examined children [16]. Mellecker et al. evaluated the intensity level of various IVGs in relation to the recommended level of physical activity. Researchers report that if an IVG is to be used to increase the physical efficiency, individual differences in the level of achieved effort and the initial level of physical efficiency should be taken into account [28]. 


\section{OXYGEN UPTAKE}

VO2 was analysed during a single IVG session. The results of the study show that during the game children reached values of $\mathrm{VO} 2$ that indicate a moderate level of physical effort [28]. Compared to inactive video games, IVGs significantly increase the amount of a child's VO2, which may be evidence of the IVG's impact on improving the body's efficiency. IVGs cause changes in the VO2 parameter similar to those occurring during traditional physical activities in natural conditions $[19,23]$.

McNarry et al. conducted a one-off IVG intervention, in which they evaluated peak VO2. The results show that IVG can contribute to the increase of energy expenditure, thus increasing the efficiency of the circulatory-respiratory system. Researchers report that gender and the initial level of a child's physical efficiency are particularly important in determining future IVG interventions to increase the level of physical activity and cardiorespiratory system fitness [24].

Studies that evaluated the impact of opponent-based games on $\mathrm{VO} 2$ showed that the presence of another player did not increase the VO2. Boys showed a greater increase in VO2 during IVGs compared to girls [23]. Indirect calorimetry methods confirm the beneficial effect of IVGs to a greater extent than accelerometer methods. Active games can significantly reduce the time spent in a sitting position, and thus affect the health indicators [29].

\section{HEART RATE}

Evaluating the heart rate (HR) during the game proves that traditional video games cause a minor change in this parameter and lower energy consumption in comparison to IVGs. Active games increase the HR by as much as $59 \%$, and energy expenditure by $224 \%$ in boys and girls, compared to energy expenditure at rest. The level of physical activity reached during an IVG is comparable to moderate intensity exercise [30].

\section{ENERGY INTAKE}

Researchers also assessed the children's energy intake (EI) and subjective appetite in the case of free access to unhealthy snacks during active and stationary video games. The research showed that the phenomenon of increased energy intake in the form of snacking was more often observed during an inactive video game. The amount of energy expenditure during IVG was not large enough to compensate for the increased consumption of snacks. During the meal consumed $1 \mathrm{~h}$ after the end of the game, the children did not show any greater energy intake, both after the inactive and interactive video game [15]. Other studies showed no differences in snacking during an active and inactive video game. By snacking, children provided a similar amount of energy during both games. Research has shown that the component of game activity did not reduce the consumption of snacks [31]. Therefore, it is necessary to restrict the children's access to snacks during the game in order to maintain its health aspects.

\section{INTERACTIVE VIDEO GAMES VS. DIFFERENT FORMS OF PHYSICAL EFFORT}

Studies compared the effects of IVGs with other forms of physical effort, e.g. treadmill walking, and it was proven that IVGs caused a comparable or better effect in terms of the analysed parameters: energy expenditure, heart rate, percentage of heart rate reserve, and perceived effort $[14,17]$. In other studies, training with the use of IVGs resulted in a lesser effect than training on a treadmill. Lower values of children's energy expenditure and heart rate during IVGs were observed [18].

\section{INTERACTIVE VIDEO GAMES AND PSYCHOLOGICAL PARAMETERS}

The researchers also analysed the effect of single-player and opponent-based IVGs. Competitive IVGs resulted in a better psychological response both in the child's emotional involvement and in the degree of perceived effort [32]. In addition, the child's energy expenditure during the opponent-based game was greater compared to games played alone [27].

Studies evaluating preferences regarding game selection proved that IVGs were eagerly chosen by children as an attractive form of entertainment and spending free time. Moreover, IVGs stimulate an increased level of physical activity. When children have a choice, they prefer IVGs to traditional inactive games [18].

\section{INTERACTIVE VIDEO GAMES - PHYSICAL ACTIVITY INTERVENTIONS}

Studies using IVGs to promote increased levels of physical activity also evaluated the effects of long-lasting interventions. Such interventions aimed to create lasting changes in the children's everyday behaviour by reducing unhealthy habits and shortening the amount of time spent in a sitting position.

\section{INTERACTIVE VIDEO GAME INTERVENTION - CHANGE OF UNHEALTHY HABITS}

Research showed that IVG interventions had a positive effect on reducing the frequency of light physical effort in favour of vigorous effort. In addition, the researchers observed a reduction in the weekly time spent by children in front of a screen by increasing periods of daily physical activity [33-38]. Extending the daily time 
that children spent being active caused higher values of moderate to vigorous physical activity $[4,39]$. IVG interventions reduced the amount of time that children spent on inactive video games, which resulted in increased physical activity during the day [40].

\section{INTERACTIVE VIDEO GAME INTERVENTION AND IMPROVEMENT OF THE BODY'S EFFICIENCY}

The results of the studies confirmed the beneficial effects of long-term exercise programs using IVGs on maximum oxygen uptake (VO2 $\max )[34,41]$. This demonstrates the impact of IVGs on improving children's cardiorespiratory fitness $[4,42]$. High values of $\mathrm{VO} 2$ max are maintained for a relatively long time, as shown by a follow-up study conducted 30 weeks after the end of the IVG intervention - more evidence of the beneficial effect of IVGs on the physical efficiency of children [35].

\section{INTERACTIVE VIDEO GAMES IN THE SCHOOL ENVIRONMENT}

Numerous studies evaluated the effects of IVG interventions in the school environment. The effects of ordinary exercises during physical education (PE) lessons were compared with IVGs. The research showed that IVGs generated higher physical activity, which resulted from the child's greater involvement in the more attractive game [39, 43]. Moreover, PE classes enriched with IVG elements had beneficial effects on children's behaviour: a positive attitude to such classes and an increased willingness to participate was observed [44]. Other studies evaluating the effect of IVGs in the school environment showed that the games were less effective compared to fitness exercises. However, the interest and involvement of children in IVG sessions was much higher compared to the fitness sessions. This showed the influence of active games on increasing the willingness of a child to participate in various forms of physical activity, offered by IVG programs [45]. However, in order for IVG to affect health parameters, an appropriate level of intensity of the game must be taken into account.

Research by Garde et al. and Mc Dougall et al., assessing the effects of free access to IVGs in the school environment, confirmed the benefits of such interventions. Children eagerly undertook physical activity in the game form and consequently, increased their daily distance travelled and extended their daily activity. During the intervention period, children took $11 \%$ more steps per day compared to the period before the intervention, and attained physical activity at a moderate or vigorous level. Free access to IVGs in schools can effectively change children's sedentary behaviours and reduce the risk of overweight and obesity. Even short periods of activity using an active video game can significantly help the children to achieve the recommended daily norm of physical activity [46, 47]. Therefore, an active video game can be an effective method of engaging children in physical activity in the school environment [48].

\section{FACTORS AFFECTING THE LEVEL OF INTEREST IN THE GAME}

The aspects of novelty and children's interest in the game have a significant impact on the increased level of physical activity during long-lasting IVG interventions. At the beginning of the intervention, children considered the game as a new experience and showed a significant increase in the level of physical activity compared to the starting values. Their interest in active video games diminished with the participation time. When a game was already known and ceased to be attractive, children lost interest and the level of their activity decreased. Studies comparing the effects of training with the use of a traditional stationary bicycle and its interactive version were conducted - the research confirmed that children preferred using an IVG to increase the level of physical activity, and IVGs increased this level more effectively compared to a stationary bicycle. However, this was observed particularly in the initial phase of the intervention $[49,50]$.

Research that assessed the impact of feedback during an IVG on the level of the MVPA indicator and satisfaction with the activity undertaken was conducted. It was shown that children, even without receiving feedback about game achievements, displayed the same level of satisfaction with the game and the level of MVPA as in the game with feedback [51]. Effective strategies are needed in order to encourage children to voluntarily participate in daily physical activity in the form of IVGs. Self-initiation and choice of activity are the factors determining the strength of motivation to take up an activity. Enjoyment, proficiency, and achievement also influence the child's interest in an activity [3]. However, it should be noted that the effectiveness of this method may diminish when a child becomes familiar with the game [4, 52-54].

\section{INTERACTIVE VIDEO GAME INTERVENTIONS AND PSYCHOLOGICAL PARAMETERS}

IVG interventions have a positive effect in terms of psychosocial functions. Children who participated in IVG sessions showed significantly higher self-esteem, social support, and self-efficacy [36].

Other studies showed that the lack of motivation and appropriate incentives for the child to undertake physical activity related to IVG would not bring the desired effect. IVGs used by children only in the home environment did not sufficiently increase the level of physical 
activity. Children who had a choice of sedentary video games and IVGs chose inactive games more often [55]. To effectively increase the level of their physical activity at home, parents should be willing to play an active game together with their children. Such participation in IVGs can effectively change children's sedentary behaviour and contribute to promoting social behaviours in the family [50]. Other studies also confirmed that the co-player's participation was important in a child's decision to play the game because they were more likely to engage in IVGs when it was possible to play with other people, especially with their peers [55].

\section{SUBJECTIVE EVALUATION OF THE GAME - INTERVIEW WITH PARENTS AND CHILDREN}

Five studies based on a thorough interview with children and their parents, who subjectively rated IVGs, were conducted. Children chose IVGs more often, primarily because of the possibility of activity during the games, which were also more social. They declared a preference to play IVGs with another player having similar skills, but when it came to inactive games, they usually played alone. Parents also preferred IVGs due to the fact that it increased the level of physical activity of their children and their greater motivation to practice specific outdoor sports after learning the rules during the virtual game [56-59].

Research that assessed how children and their parents perceived IVGs, and what the barriers associated with the use of this type of games were, was also conducted. The children took part in a 30-minute IVG session, and immediately after the game, focus group interviews were conducted. Both children and parents saw the positive aspects of an active game and stated that this was a good way to increase the level of fitness and physical activity. Older children noticed much greater health benefits of an interactive game. As the most common barriers, parents mentioned the cost associated with the purchase of the IVG kit and the lack of convenient conditions for this type of game at home. Other concerns included the probability of a child replacing outdoor physical activity with IVGs. However, parents recognised that physical activity with the use of new technologies was better than passively spending time in front of a screen [60].

\section{CONCLUSIONS}

Nowadays, the lack of children's physical activity is an important health problem. It can be solved only through a comprehensive approach consisting of education and interventions that use attractive forms of daily physical activity. Primarily, it is necessary to promote traditional health attitudes with full stimulation of physical development, such as physical education, sports, and recreation. Systematic trainings shape the body and help maintain physical fitness, whereas team sports help to develop social attitudes. Modern technologies, including IVGs, can be a valuable supplement to traditional forms of physical activity.

Nowadays, when the popularity of inactive video games is constantly growing, the promotion of active games can effectively encourage the group of healthy children to take physical activity independently. Active video games should not be promoted as the only form of activity, but they are common in many homes and educational institutions. Children use these games very often, and because of their popularity IVGs need to be considered for the benefit of children's health.

Preliminary reports present IVGs as an effective method of promoting independent physical activity. Studies comparing IVG effects with other forms of physical exercise showed that active games generated increased energy expenditure of children, which corresponded to mild, moderate, or even intensive physical activity levels $[11,12$, 14-20]. IVGs are an accessible and active form of spending free time in a home environment. Most studies confirm that children who had IVG systems were more likely to choose active games instead of inactive ones [56-59]. Thanks to active video games, the children changed their daily habits and limited the time spent in a sedentary position during inactive video games. This had a beneficial effect on increasing children's energy expenditure and improved their physiological parameters. In addition, a beneficial impact on VO2 during one-off interventions with IVGs has been observed [19, 23, 24, 29]. To improve the overall physical fitness of a child, longer-term IVG programs should be applied [4, 34, 35, 41, 42]. However, studies have shown that the level of interest in active video games decreases with the time of participation in the game. Such a phenomenon is not observed so often in the traditional forms of physical activity. When the interactive game is not new and attractive anymore, children lose interest and the level of their activity decreases $[49,50]$. Therefore, various IVG programs should be implemented. Peers or parents should also be involved, to encourage children to continue this form of activity. This will prevent an excessive drop in interest, because children prefer team games with competitive elements [27, 32, 36, 50, 55].

Nowadays, when children are functioning in a virtual space, traditional forms of physical activity should be promoted as a basic method for stimulating psychomotor development. Modern technologies should only be complementary activities. In the future, it will be seen whether IVG programs can have a beneficial effect on increasing the daily physical activity of children and limiting the time spent in a sedentary position.

\section{DISCLOSURE}

The authors declare no conflict of interest. 


\section{REFERENCES}

1. Staiano AE, Abraham AA, Calvert SL. Motivating Effects of Cooperative Exergame Play for Overweight and Obese Adolescents. J Diabetes Sci Technol 2012; 6: 812-819.

2. Lu AS, Baranowski T, Hong SL, et al. The Narrative Impact of Active Video Games on Physical Activity Among Children: A Feasibility Study. J Med Internet Res 2016; 18: 272.

3. Baranowski T, Abdelsamad D, Baranowski J, et al. Impact of an Active Video Game on Healthy Children's Physical Activity. Pediatrics 2012; 129: 636-642.

4. Chen H, Sun H. Effects of Active Videogame and Sports, Play, and Active Recreation for Kids Physical Education on Children's Health-Related Fitness and Enjoyment. Games Health J 2017; 6: 312-318.

5. Janssen I, Leblanc AG. Systematic review of the health benefits of physical activity and fitness in school-aged children and youth. Int J Behav Nutr Phys Act 2010; 7: 40.

6. Hallal PC, Andersen LB, Bull FC, et al. Global physical activity levels: surveillance progress, pitfalls, and prospects. Lancet 2012; 380: 247-257.

7. Leatherdale ST, Ahmed R. Screen-based sedentary behaviours among a nationally representative sample of youth: are Canadian kids couch potatoes? Chronic Dis Inj Can 2011; 31: 141-146.

8. Han JC, Lawlor DA, Kimm SYS. Childhood Obesity - 2010: Progress and Challenges. Lancet 2010; 375: 1737-1748.

9. Andersen LB, Harro M, Sardinha LB, et al. Physical activity and clustered cardiovascular risk in children: a cross-sectional study (The European Youth Heart Study). Lancet 2006; 368: 299-304.

10. Tremblay MS, LeBlanc AG, Kho ME, et al. Systematic review of sedentary behaviour and health indicators in school-aged children and youth. Int J Behav Nutr Phys Act 2011; 8: 98.

11. Lanningham-Foster L, Foster R, McCrady S, et al. Activity promoting games and increased energy expenditure. J Pediatr 2009; 154: 819-823.

12. Maddison R, Mhurchu C, Jull A, et al. Energy Expended Playing Video Console Games: An Opportunity to Increase Children's Physical Activity? Pediatr Exerc Sci 2007; 19: 334-343.

13. Peng W, Crouse JC, Lin JH. Using active video games for physical activity promotion: a systematic review of the current state of research. Health Educ Behav 2013; 40: 171-192.

14. Lanningham-Foster L, Jensen TB, Foster RC, et al. Energy expenditure of sedentary screen time compared with active screen time for children. Pediatrics 2006; 118: 1831-1835.

15. Allsop S, Green BP, Dodd-Reynolds CJ, et al. Comparison of shortterm energy intake and appetite responses to active and seated video gaming, in 8-11-year-old boys. Br J Nutr 2016; 115: 1117-1125.

16. Graves L, Stratton G, Ridgers ND, et al. Energy expenditure in adolescents playing new generation computer games. Br J Sports Med 2008; 42: 592-594.

17. Canabrava K, Faria FR, De Lima J, et al. Energy Expenditure and Intensity of Active Video Games in Children and Adolescents. Res Q Exerc Sport 2018; 89: 47-56.

18. Graves L, Ridgers ND, Williams K, et al. The Physiological Cost and Enjoyment of Wii Fit in Adolescents, Young Adults, and Older Adults. J Phys Act Health 2010; 7: 393-401.

19. Smallwood SR, Morris MM, Fallows SJ, et al. Physiologic Responses and Energy Expenditure of Kinect Active Video Game Play in Schoolchildren. Arch Pediatr Adolesc Med 2012; 166: 1005-1009.

20. Mellecker R, McManus A. Energy expenditure and cardiovascular responses to seated and active gaming in children. Arch Pediatr Adolesc Med 2008; 162: 886-891.
21. Graves LE, Ridgers ND, Stratton G. The contribution of upper limb and total body movement to adolescents' energy expenditure whilst playing Nintendo Wii. Eur J Appl Physiol 2008; 104: 617-623.

22. Lam J, Sit C, McManus AM. Play Pattern of Seated Video Game and Active "Exergame" Alternatives. J Exerc Sci Fit 2011; 9: 24-30.

23. Siegmund LA, Naylor JB, Santo AS, et al. The effect of a peer on VO2 and game choice in 6-10 year old children. Front Physiol 2014; 5: 202.

24. McNarry MA, Mackintosh KA. Investigating the Relative Exercise Intensity of Exergames in Prepubertal Children. Games Health J 2016; 5: 135-140.

25. Cavill N, Biddle S, Sallis JF. Health Enhancing Physical Activity for Young People: Statement of the United Kingdom Expert Consensus Conference. Pediatr Exerc Sci 2001; 13: 12-25.

26. Pate RR, Pratt M, Blair SN, et al. Physical activity and public health: a recommendation from the Centers for Disease Control and Prevention and the American College of Sports Medicine. JAMA 1995; 273: 402-407.

27. Verhoeven K, Abeele VV, Gers B, et al. Energy Expenditure During Xbox Kinect Play in Early Adolescents: The Relationship with Player Mode and Game Enjoyment. Games Health J 2015; 4: 444-451.

28. Mellecker RR, McManus AM. Active video games and physical activity recommendations: a comparison of the Gamercize Stepper, XBOX Kinect and XaviX J-Mat. J Sci Med Sport 2014; 17: 288-292.

29. Reading SA, Prickett K. Evaluation of Children Playing a New-Generation Motion-Sensitive Active Videogame by Accelerometry and Indirect Calorimetry. Games Health J 2013; 2: 166-173.

30. Straker L, Abbott R. Effect of screen-based media on energy expenditure and heart rate in 9- to 12-year-old children. Pediatr Exerc Sci 2007; 19: 459-471.

31. Mellecker RR, Lanningham-Foster L, Levine JA, et al. Energy intake during activity enhanced video game play. Appetite 2010; 55: 343-347.

32. Lisón JF, Cebolla A, Guixeres J, et al. Competitive active video games: Physiological and psychological responses in children and adolescents. Paediatr Child Health 2015; 20: 373-176.

33. Maloney AE, Bethea TC, Kelsey KS, et al. A pilot of a video game (DDR) to promote physical activity and decrease sedentary screen time. Obesity 2008; 16: 2074-2080.

34. Lau PW, Wang JJ, Maddison R. A Randomized-Controlled Trial of School-Based Active Videogame Intervention on Chinese Children's Aerobic Fitness, Physical Activity Level, and Psychological Correlates. Games Health J 2016; 5: 405-412.

35. Bethea TC, Berry D, Maloney AE, et al. Pilot Study of an Active Screen Time Game Correlates with Improved Physical Fitness in Minority Elementary School Youth. Games Health J 2012; 1: 29-36.

36. Gao Z, Huang C, Liu T, et al. Impact of interactive dance games on urban children's physical activity correlates and behavior. J Exerc Sci Fit 2012; 10: 107-112.

37. Gao Z, Podlog L. Urban Latino children's physical activity levels and performance in interactive dance video games: effects of goal difficulty and goal specificity. Arch Pediatr Adolesc Med 2012; 166: 933-937.

38. Graves LE, Ridgers ND, Atkinson G, et al. The Effect of Active Video Gaming on Children's Physical Activity, Behavior Preferences and Body Composition. Pediatr Exerc Sci 2010; 22: 535-546.

39. Maloney AE, Stempel A, Wood ME, et al. Can Dance Exergames Boost Physical Activity as a School-Based Intervention? Games Health J 2012; 1: 416-421.

40. Ni Mhurchu C, Maddison R, Jiang Y, et al. Couch potatoes to jumping beans: a pilot study of the effect of active video games on physical activity in children. Int J Behav Nutr Phys Act 2008; 5: 8. 
41. Owens SG, Garner JC 3rd, Loftin JM, et al. Changes in physical activity and fitness after 3 months of home Wii Fit ${ }^{\text {tm }}$ use. J Strength Cond Res 2011; 25: 3191-3197.

42. Gao Z, Hannan P, Xiang P, et al. Video game-based exercise, Latino children's physical health, and academic achievement. Am J Prev Med 2013; 44: 240-246.

43. Shayne RK, Fogel VA, Miltenberger RG, et al. The effects of exergaming on physical activity in a third-grade physical education class. J Appl Behav Anal 2012; 45: 211-215.

44. Lwin MO, Malik S. The efficacy of exergames-incorporated physical education lessons in influencing drivers of physical activity: A comparison of children and pre-adolescents. Psychol Sport Exerc 2012; 6: 756-760.

45. Sun H. Exergaming impact on physical activity and interest in elementary school children. Res Q Exerc Sport 2012; 83: 212-220.

46. Garde A, Umedaly A, Abulnaga SM, et al. Evaluation of a Novel Mobile Exergame in a School-Based Environment. Cyberpsychol Behav Soc Netw 2016; 19: 186-192.

47. McDougall J, Duncan MJ. Children, video games and physical activity: An exploratory study. Int J Disabil Hum Dev 2008; 7: 89-94.

48. Duncan MJ, Birch S, Woodfield L, et al. Physical activity levels during a 6-week, school-based, active videogaming intervention using the gamercize power stepper in british children. Med Sport 2011; 15: 81-87.

49. Mark RS, Rhodes RE. Testing the effectiveness of exercise videogame bikes among families in the home-setting: a pilot study. J Phys Act Healt 2013; 10: 211-221.

50. Rhodes RE, Blanchard CM, Bredin SSD, et al. Stationary cycling exergame use among inactive children in the family home: a randomized trial. J Behav Med 2017; 40: 978-988.

51. Chen H, Sun H. The Effects of Active Videogame Feedback and Practicing Experience on Children's Physical Activity Intensity and Enjoyment. Games Health J 2017; 6: 200-204.

52. Sun H. Impact of exergames on physical activity and motivation in elementary school students: A follow-up study. J Sport Health Sci 2013; 2: 138-145.

53. Garde A, Chowdhury M, Rollinson AU, et al. A Multi-Week Assessment of a Mobile Exergame Intervention in an Elementary School. Games Health J 2018; 7: 1-8.

54. Norman GJ, Adams MA, Ramirez ER, et al. Effects of Behavioral Contingencies on Adolescent Active Videogame Play and Overall Activity: A Randomized Trial. Games Health J 2013; 2: 158-165.

55. Chin A Paw MJ, Jacobs WM, Vaessen EP, et al. The motivation of children to play an active video game. J Sci Med Sport 2008; 11:163-166.

56. Simons M, Bernaards C, Slinger J. Active gaming in Dutch adolescents: a descriptive study. Int J Behav Nutr Phys Act 2012; 9: 118.

57. De Vet E, Simons M, Wesselman M. Dutch children and parents' views on active and non-active video gaming. Health Promot Int 2014; 29: 235-243.

58. Rhodes RE, Nwachukwu N, Quinlan A. Family Exergaming: Correlates and Preferences. Games Health J 2018; 7: 188-196.

59. Forde C, Hussey J. How Children Use Active Videogames and the Association Between Screen Time and Physical Activity. Games Health J 2015; 4: 312-317.

60. Dixon R, Maddison R, Ni Mhurchu C, et al. Parents' and children's perceptions of active video games: a focus group study. J Child Health Care 2010; 14: 189-199. 